\title{
Resenhas
}





\section{A Monarquia e o mundo dos negócios}

A IMPORTÂNCIA da monarquia brasileira foi reconsiderada entre nós a partir dos anos 1970, com base na renovação metodológica dos estudos de história política, internacionalmente desenvolvida. Longamente tido como "flor exótica" no continente americano, ficou o regime muito tempo bastante esquecido dos estudos considerados "críticos", em que se valorizavam, sobretudo, a formação escravista colonial e a sua desagregação, a partir dos anos 70 do século XIX, a par da própria desagregação do Império. Mas, por intermédio de estudos em grande parte realizados nos cursos de pós-graduação das nossas universidades, com base em intensa pesquisa empírica, a formação e desenvolvimento da monarquia brasileira vêm se mostrando um campo fértil para a compreensão das relações entre sociedade e Estado no Brasil.

A obra ora em apreço representa um salto qualitativo na renovação desse campo historiográfico. Nela se realizou, por intermédio de um conjunto de trabalhos desenvolvidos nos cursos de pós-graduação da USP e da Unicamp, uma articulação teórico-historiográfica entre a instituição do Estado - que, na sua própria forma monárquica, ao contrário do que por muito tempo se pensou, foi liberal desde os primórdios da Independência e o mundo dos negócios, num país em que as atividades econômicas urbanas tiveram um peso bem maior do que se costuma considerar. Trata-se de relações contraditórias, que não se explicam pelo que em certos vetores analíticos se avalia como "distorções" das realidades brasi- leiras, ou ibero-americanas, consideradas atrasadas, periféricas, imperfeitamente capitalistas e liberais. Pelo contrário, conforme explicitam na Introdução as organizadoras do livro, as relações sociedade-Estado desenvolvidas no Brasil independente e, num sentido amplo, as próprias relações coloniais decorreram das contradições que marcaram os próprios fatores originários do liberalismo.

Abrangendo dois grandes "momentos" da constituição e desenvolvimento do Brasil enquanto país independente, essas questões são analisadas, na primeira parte do livro, basicamente, à luz da Independência; na segunda parte, trata-se de se observar as relações sociedade-Estado nas regências e na ainda conturbada década da Maioridade, seguindo-se o desenvolvimento do jogo político e empresarial nas décadas seguintes, num Império já estabilizado.

Como tem mostrado a historiografia mais recente, no plano socioeconômico a nossa independência assentou-se em grande medida em determinados grupos das elites coloniais, que se desenvolveram sobretudo no século XVIII no sudeste e sul da colônia. A formação desses grupos e a articulação entre eles é elemento capital para se compreender, entre outros fatores, a maneira pela qual diferentes regiões da Colônia Brasil, longamente pouco identificadas entre si, uniram-se num todo maior. Nessa dimensão, Ana Paula Médici mapeou os grupos de contratadores de impostos, envolvidos numa extensa rede de produção e comércio na então capitania de São Paulo. Capitania que, junto com Minas Gerais, teve papel 
fundamental no modo pelo qual se realizou a independência, com base no centro monárquico estabelecido no Rio de Janeiro. De acordo com Vera Lucia N. Bittencourt, esse processo resultou de um complexo jogo de articulações políticas, com bases socioeconômicas. Conforme Norbert Elias (O processo civilizador: formação do Estado e civilização), foi o comércio, diferentemente das atividades estritamente rurais, que possibilitou o alargamento das fronteiras entre áreas antes apartadas, favorecendo posturas de negociação para a solução dos impasses políticos e o desenvolvimento de um Estado centralizado. Tese que se confirma na recomposição sociopolítica, feita pela autora, de um momento ainda muito pouco estudado na historiografia: a regência de $\mathrm{D}$. Pedro, entre a partida de D. João VI para Lisboa e a declaração da independência. Inicialmente frágil, a autoridade do príncipe aos poucos se consolidou, no concerto das alianças e acordos entre a autoridade estatal e os grupos civis.

Mas a atuação desses grupos já adquirira feição específica, dada a possibilidade de maturação política decorrente da presença da corte portuguesa no Rio de Janeiro. Próximos ao núcleo central do poder metropolitano, os elementos de maior relevância socioeconômica a ele se articulavam, não apenas no plano estritamente econômico, mas no da busca de status social e político, o que, entre outros fatores, levava ao patrocínio das festas públicas realizadas na corte joanina, conforme a exposição de Emilio Carlos R. Lopes.

Fundamentalmente, foram se constituindo, de modo mais ou menos explícito, diferentes projetos para o Brasil em formação, vivenciando-se um amplo processo de disputas políticas, que, com a Revolução Liberal do Porto em 1820, tomou impulso e adquiriu grande visibilidade. Nesse contexto, não faltou a ocorrência de embate violento, consubstanciado nos conflitos ocorridos na Praça do Comércio do Rio de Janeiro, quando da reunião montada devido às demandas de representação política surgidas com a Revolução. Cecília Helena S. Oliveira desvenda a rede de relações sociais ocultas sob o jogo político que se realizava na corte, envolvendo elementos da burocracia e diferentes grupos civis, em que se destacou um grupo de liberais aparentemente mais radicais, responsáveis pela convocação da reunião. Produtores inicialmente de menor porte financeiro do que os abastados comerciantes de "grosso trato" advogavam, a par de reformas políticas radicais, no quadro do liberalismo, a defesa do comércio e da indústria "nacionais" e outras medidas de proteção ao trabalho, urbano e rural. Reivindicações essas que propiciaram a mobilização de diferentes camadas da população.

Nessas disputas, o violento episódio - ainda historiograficamente pouco conhecido - é emblemático para nele se distinguirem as formas de atuação e de justificativas políticas dos grupos envolvidos, bem como as diferentes interpretações dos contemporâneos a seu respeito. Perdendo o controle de uma reunião por eles articulada, os "radicais" procuraram se desvincular da massa que atraíram com suas propostas, na medida em que essa apresentou comportamentos políticos próprios.

Argumenta-se neste livro, já na sua Introdução, a compatibilidade entre continuidade do escravismo e adoção do liberalismo no Brasil independente, o que é fundamental não só para se enten- 
der a devida complexidade das relações sociedade-Estado no Brasil até o terceiro quartel do século XIX, como o liberalismo em si. Observe-se que a conservação do escravismo constitui fator que, numa perspectiva linear - na contramão das abordagens analíticas apresentadas na introdução e nos capítulos deste trabalho - é utilizada para se defender a tese do "atraso" brasileiro, considerado incompatível com o ser liberal. Nessa dimensão, João Eduardo F. Scanavini relata as discussões parlamentares que se seguiram à assinatura do tratado anglo-brasileiro de 1826, proibindo o tráfico atlântico de escravos. Deputados de tendências políticas distintas se alternaram na sua condenação (maioria) e na sua defesa (minoria), em termos amplamente ajustados ao jogo entre as competências do Executivo e do Legislativo, como costuma acontecer nos Estados de institucionalização liberal.

A segunda parte do livro aborda um Império que, embora já constituído, ainda sofria contestações importantes, até se "estabilizar" nos anos 50 do século em apreço. Importa perceber a fluidez entre posturas liberais e conservadoras que se articulavam no mundo dos negócios, embora, no plano político, se desdobrassem em matizes diferenciados, cujos sentidos, como argumenta Eric Hörner, precisam ser revistos. Problematizam-se as interpretações a respeito, em grande parte decorrentes do anacronismo de se pensar a primeira metade do século XIX em razão das cristalizações ocorridas no seu último quartel.

Embora em processo de estabilização com a Maioridade de D. Pedro II - a qual, em 1840, forçou o fim da conturbada experiência regencial -, o Império brasileiro ainda sofreu uma expressiva contestação com a Revolução Praieira, ocorrida em Pernambuco em 1848, denominada "liberal". Izabel de Andrade Marson revela exemplarmente os limites desse projeto. Explorando as contradições dos discursos praieiros e conservadores, mostra como a defesa da proteção ao comércio de retalho e da chamada "indústria nacional", em contraposição ao "laissez-faire" conservador, formou um delineamento ideológico entre os "revolucionários" da Praieira, chamados liberais, e os conservadores, adeptos do "progresso". "Progresso" esse simultaneamente aberto ao mercado internacional e, internamente, representado pelos proprietários rurais mais ricos, financeiramente capazes de transformar tecnologicamente a produção do açúcar.

O projeto "liberal", contudo, apoiado pelos proprietários rurais mais pobres e por diferentes camadas urbanas, tinha como limite fundamental, desvelado pela autora, a seguinte contradição: boa parte da massa urbana dos seus adeptos agia em razão de interesses/representações passadistas, de caráter artesanal-corporativista, enquanto o projeto de "indústria nacional liberal" trazia implícita a transformação dessas figuras sociais em mão de obra para as fábricas. Propositura essa naturalmente camuflada nos discursos liberais, de grande mobilização popular. Numa leitura linear, esse quadro propiciou, por muito tempo, uma interpretação da Praieira como uma revolução efetivamente popular, até mesmo socialista. Observe-se, nesse cenário, a recorrência do que Cecília Helena S. Oliveira qualificou como a "astúcia liberal", na década de 1820, quando os liberais envolvidos nas disputas da Praça do Comércio se desvencilharam das camadas efetivamente populares que os apoiavam. 


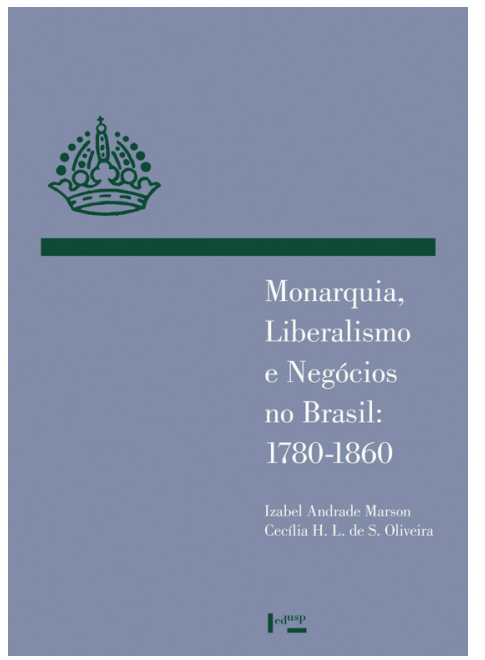

MARSON, I. A.; OLIVEIRA, C. H. L. de S. (Org.) Monarquia, liberalismo e negócios no Brasil: 1780-1860.

São Paulo: Edusp, 2013.

$\mathrm{Na}$ sequência das "revoluções", a "conciliação" - ainda que precária enquanto tal - indica uma institucionalização política que teria permitido aos seus atores arrojarem-se na fluidez das relações entre "política, partidos e empreendimentos".

Dessa forma, interesses mais particularizados se apresentaram na trajetória político-empresarial de Teófilo Ottoni, que, com imagem marcadamente liberal, como mostra Maria Cristina N. Ferreira Neto, teria na realidade se envolvido num jogo de alianças com políticos conservadores, visando o favorecimento legal, por intermédio de aprovações parlamentares, das iniciativas do seu empreendimento. De forma semelhante, como expõe Eide Sandra A. Abreu, o liberal Tavares Bastos, partícipe da contraditória Liga Progressista, compactuou com um conjunto de trâmites escusos entre público e privado - envolvendo o Parlamento, autoridades do Executivo brasileiro e diplomatas - para obter a aprovação de uma companhia de navio a vapor estadunidense e favorecer a imigração daquele país para o Brasil. Cabe frisar que, na contramão do que sucedera no período da Independência e na Revolução Praieira, foram os conservadores, nesse momento, a defenderem o que seria a "indústria nacional" no contexto.

Conforme Habermas (Mudança estrutural da esfera pública), com o advento do Estado liberal, a esfera pública, em grande parte consubstanciada no Parlamento, passou a ser dirigida, na contramão do Estado absolutista, a partir da esfera privada, constituindo-se assim contraditoriamente o liberalismo, desde os seus primórdios, entre as suas dimensões públicas e privadas, entre um discurso descentralizador e o Estado impositivo. Estado esse que, no caso do Brasil, foi grandemente pensado como "demiurgo" da nossa sociedade, tese cabalmente desmentida pela obra ora em apreço.

Marisa Saenz Leme é professora do Departamento de História da Faculdade de Ciências Humanas e Sociais, Universidade Estadual Paulista "Júlio de Mesquita Filho", campus de Franca (SP).

@ - saenzl@terra.com.br

${ }^{\text {I }}$ Faculdade de Ciências Humanas e Sociais, Departamento de História, Universidade Estadual Paulista "Júlio de Mesquita Filho", Franca/SP, Brazil. 